\title{
Producción de la proteína recombinante JAK2 de ratón
}

\author{
Ruth E. Garzón, Amílcar Flores, Cecilia Anzola, Myriam Sánchez de Gómez \\ Laboratorio de Hormonas, Departamento de Química, Universidad Nacional de Colombia, \\ Santa Fe de Bogotá, D.C., Colombia
}

\begin{abstract}
Resumen
El presente trabajo describe la producción de la proteína recombinante JAK2, empleando un sistema de vectores de expresión baculovirales. La infección de células Sf9, derivadas del tejido de ovario de Spodoptera frugiperda, permitió establecer las condiciones óptimas de dilución del virus en $10 \mu \mathrm{l} / \mathrm{ml}$ de medio y de tiempo de recolección en 72 horas postinfección. Se recolectaron y ultrafiltraron extractos correspondientes a la infección de $5 \mathrm{x}$ $10^{7}$ células, aproximadamente, y se sometieron a cromatografía de intercambio iónico (DEAE-Sephacel), lográndose purificar parcialmente la proteína JAK2 por medio de un gradiente continuo de fuerza iónica ( $\mathrm{NaCl} 10-500 \mathrm{mM}$ ). La presencia de JAK2 se verificó por Western blot, empleando un anticuerpo policlonal producido en conejo contra los residuos 758-776 de JAK2 de ratón. Los resultados indicaron que la proteína obtenida por este sistema de expresión se sintetiza en forma fosforilada/activada.
\end{abstract}

Palabras clave: JAK2, hormona de crecimiento (HG), receptor de la hormona de crecimiento (GHR), baculovirus.

\section{Production of mouse recombinant JAK2 protein}

\begin{abstract}
This work describes the production of JAK2 by recombinanı methods, using a baculovirus expression vector. Sf9 cells from the ovary tissue of Spodoptera frugiperda were infected with an optimal virus dilution of $10 \mu \mathrm{l} / \mathrm{ml}$ medium and harvest was done at $72 \mathrm{~h}$ postinfection. Approximately $5 \times 10^{7}$ cells were infected, extracts were collected, ultrafiltered and subjected to ionic exchange chromatography on DEAE-Sephacel, and JAK2 was partially purified by a continuos ionic gradient (10-500 $\mathrm{mM} \mathrm{NaCl}$ ). JAK2 was identified by Western blot with a polyclonal antibody raised in rabbits against $758-776$ residues from murine JAK2. Results showed that the protein obtained by this method is in phosphorylated/ activated state.
\end{abstract}

Key words: JAK2, growth hormone (GH), growth hormone receptor (GHR), baculovirus.

La comunicación entre células en los sistemas inmune y hematopoyético se lleva a cabo a través de factores solubles o proteínas mediadoras, pertenecientes a la familia de proteínas HBP (helix bundle protein), de la que forman parte varias

Correspondencia: Myriam Sánchez de Gómez, Diagonal 120A No.62A-60, Apartamento 501, Santa Fe de Bogotá, D.C.

Recibido: 13/08/99; aceptado: 19/11/99 hormonas (HG, PRL), citocinas (IL-2 a IL-7) y factores de crecimiento (GM-CSF). La mayoría de los miembros de esta familia manifiestan un amplio rango de efectos biológicos sobre varias células y tejidos a través de receptores específicos, miembros de la superfamilia de receptores de citocinas (1-3). Los receptores de esta familia carecen de actividad catalítica intrínseca en su dominio citoplasmático por lo que requieren de 
proteínas cinasas no receptoras para continuar con la señalización. Estudios recientes han mostrado que miembros de la familia de proteínas tirosina-cinasas denominadas Janus kinasas (JAK), se asocian con una región próxima a la membrana, más corrientemente conocida como 'caja 1', fosforilándose rápidamente en tirosina y provocando la fosforilación del receptor luego de la unión del ligando. Las JAK son proteínas de $130 \mathrm{kDa}$, aproximadamente, que carecen de dominios $\mathrm{SH} 2 / \mathrm{SH} 3$ (4) y contienen dos dominios cinasa, el primero de ellos con actividad catalítica y el segundo semejante al cinasa, pero que carece de los aminoácidos necesarios para encontrarse activo (5). Hay receptores individuales que se asocian o requieren de uno o más miembros conocidos de la familia, incluidos JAK1, JAK2, JAK3 y Tyk2. Los sustratos de las JAK son proteínas que se fosforilan en tirosina, migran al núcleo y participan en la activación de la transcripción de genes que están involucrados en el crecimiento, diferenciación o funciones celulares. La unión de la hormona de crecimiento a su receptor en células blanco, desencadena una cascada de transducción de señales en las que se ve directamente involucrada la tirosina cinasa citoplasmática JAK2 (6-8). No está claro todavía el mecanismo por el cual se forma el complejo receptor JAK2 y la manera en que esta cinasa se activa después de la interacción.

El propósito de este trabajo fue obtener la proteína JAK2 recombinante utilizando un sistema basado en células de insecto que actúan como hospederas para la expresión de genes contenidos en baculovirus recombinantes (BEVS) (9). Si se dispone de cantidades adecuadas de la proteína JAK2, será posible profundizar en los mecanismos celulares de este proceso. Estos estudios consistirian en la utilización de péptidos sintéticos correspondientes a la secuencia de la caja $1 \mathrm{del}$ receptor de HG, con los cuales se lograría esclarecer la interacción in vitro JAK2-GHR.

\section{Materiales y métodos}

\section{Cultivo celular}

Las células Sf9 se cultivaron a $28^{\circ} \mathrm{C}$, en medio libre de suero SF900II (GIBCO-Life Technologies), suplementado con penicilina $50 \mathrm{U} / \mathrm{ml}$, estreptomicina $50 \mu \mathrm{g} / \mathrm{ml}$ y anfotericina B $25 \mu \mathrm{g} / \mathrm{ml}$ (SIGMA). Para la infección, se empleó una construcción de baculovirus recombinante, la cual contiene el cADN de JAK2 de ratón. La construcción del vector fue realizada por el doctor Olli Silvennoinen en el Instituto de Tecnología Médica de la Universidad de Tampere, Finlandia.

\section{Determinación del título del baculovirus recombinante y del tiempo óptimo de recolección de las células infectadas}

Las células Sf9 crecieron en platos de poliestireno de $60 \mathrm{~mm}$ (Nunc) a una concentración de $1 \times 10^{6}$ células, hasta una confluencia de $50 \%$. En la determinación del título se adicionaron cantidades crecientes de solución viral $(10 \mu \mathrm{l}-150 \mu \mathrm{l}$ de solución viral/ml de medio), recolectando y lisando las células a las 72 horas postinfección. El tiempo óptimo de recolección de la proteína se determinó empleando la dilución óptima de virus y recolectando las células cada 24 horas hasta alcanzar las 144 horas postinfección.

\section{Lisis celular}

Las células se recolectaron en $\mathrm{PBS} / \mathrm{Na}_{3} \mathrm{VO}_{4}(1$ $\mathrm{mM}$ ) frío, a $10.000 \mathrm{~g}$ durante 15 minutos y se lisaron en buffer frío de lisis (Tris- $\mathrm{HCl} 50 \mathrm{mM}, \mathrm{pH} 8,0$, tritón X-100 1\%, NaCl 150 mM, EDTA 5 mM, DTT $1 \mathrm{mM}$, PMSF $1 \mathrm{mM}, \mathrm{Na}_{3} \mathrm{VO}_{4} 1 \mathrm{mM}$, aprotinina 3 $\mu \mathrm{g} / \mathrm{ml}$, leupeptina $2 \mu \mathrm{g} / \mathrm{ml}$, pepstatina $2 \mu \mathrm{g} / \mathrm{ml}$ y glicerol $10 \%$ ), y se sometieron a incubación sobre hielo durante 15 minutos. El material insoluble se separó a $20.000 \mathrm{~g}$ durante 15 minutos y el sobrenadante se almacenó a $-70^{\circ} \mathrm{C}$.

\section{Western blot}

Las proteínas contenidas en los extractos totales se separaron por SDS-PAGE en un gel de $7,5 \%$ y se transfirieron durante 2 horas a membranas Hybond-PVDF (Amersham). Las membranas se bloquearon durante toda la noche a $4^{\circ} \mathrm{C}$ con leche descremada a $5 \%$ disuelta en TBS-Tween (Tris$\mathrm{HCl} 20 \mathrm{mM}, \mathrm{pH} 7,4, \mathrm{NaCl} 150 \mathrm{mM}$, Tween 20 $0,05 \%$ ). Se incubó durante una hora con anticuerpo policlonal anti-JAK2 (Upstate Biotechnology Inc.) en dilución 1:2.000 y durante otra hora con anticuerpo secundario anti-conejo lgG de ratón conjugado a peroxidasa (Amersham) en dilución $1: 3.000$. Las proteínas inmunorreactivas se 
visualizaron por quimioluminiscencia $E C L$ (Amersham).

\section{Inmunoprecipitación}

Los extractos celulares (1 $\mathrm{mg}$ de proteína total) se sometieron a inmunoprecipitación con $5 \mu \mathrm{l}$ de anti-JAK2 en buffer de lisis -tritón 0,1\%-incubando con agitación constante durante una hora a temperatura ambiente. Se adicionaron $50 \mu \mathrm{l}$ de proteína A-Sepharosa-8B (Pharmacia) y se continuó la incubación durante una hora. El inmunocomplejo se lavó 3 veces con buffer de lisis $y$, posteriormente, se utilizó en el ensayo cinasa o en el reconocimiento con anti-fosfotirosina.

\section{Ensayo cinasa}

El inmunocomplejo se lavó 3 veces en buffer cinasa (HEPES $10 \mathrm{mM}$, pH 7,6, NaCl $50 \mathrm{mM}$, $\mathrm{Na}_{3} \mathrm{VO}_{4} 0,2 \mathrm{mM}, \mathrm{MnCl}_{2} 5 \mathrm{mM}, \mathrm{MgCl}_{2} 5 \mathrm{mM}$ ) y se resuspendió en $40 \mu \mathrm{l}$ de buffer cinasa que contenía $5 \mu \mathrm{Ci}$ de $\left(\gamma^{32} \mathrm{P}\right)$-ATP (Amersham), incubando a 30 ${ }^{\circ} \mathrm{C}$ durante 30 minutos. La reacción fue suspendida por adición de $1 \mathrm{ml}$ de buffer frío de lisis $y$, posteriormente, se lavó 3 veces con buffer de lisis. Las proteínas se separaron por SDS-PAGE en geles de $7,5 \%$ y se visualizaron por autorradiografía revelándolas a los cuatro días de exposición a $-70{ }^{\circ} \mathrm{C}$. Se utilizaron células BRL-4 (células de rata Búfalo, establemente transfectadas con el GHR) como control positivo que expresan JAK2 de forma endógena, estimuladas una hora antes de la preparación de los extractos con $500 \mu \mathrm{l}$ de una solución de $\mathrm{H}_{2} \mathrm{O}_{2}(25 \mu \mathrm{M})$ y $\mathrm{Na}_{3} \mathrm{VO}_{4}(5 \mathrm{mM})$, lo que activa la producción de cinasas en la célula $y$, como control negativo, células Sf9 sin infectar.

\section{Fosforilación de JAK2}

El inmunocomplejo se resuspendió en buffer Laemli $4 X$, dejándolo en ebullición durante 4 minutos; luego, se centrifugó y el sobrenadante se sembró en un gel de $7,5 \%$, transfiriéndolo posteriormente a membranas PVDF. Las proteínas fosforiladas se visualizan por incubación con anticuerpo primario anti-fosfotirosina PY20 en dilución (1:1.000) y, posteriormente, con anticuerpo secundario monoclonal anti-ratón IgG acoplado a peroxidasa en dilución (1:1.000), siguiendo el protocolo que se describió para el Western blot de JAK2.

\section{Purificación parcial de JAK2 recombinante por cromatografía de intercambio iónico en DEAE- Sephacel}

Los extractos celulares provenientes de la infección (en condiciones óptimas) de alrededor de $5 \times 10^{7}$ células Sf9, se concentraron por ultrafiltración (filtro Sartorius PM 30) y se aplicaron a una columna de DEAE-Sephacel $(1,5 \times 10 \mathrm{~cm})$, equilibrada con buffer (Tris- $\mathrm{HCl} 20 \mathrm{mM}$, pH 8,0, $\mathrm{NaCl} 10 \mathrm{mM}$, EDTA $1 \mathrm{mM}$, DTT 0,5 mM, PMSF $\left.0,2 \mathrm{mM}, \mathrm{NaN}_{3} 0,02 \%\right)$. La elución se realizó en el buffer de equilibrio y la fracción de proteína retenida se eluyó al aplicar un gradiente continuo de fuerza iónica ( $\mathrm{NaCl} 10-500 \mathrm{mM}$ ). La proteína eluida se monitorizó por lectura de absorbancia a $280 \mathrm{~nm}$ y la presencia de JAK2 se estableció por medio de Western blot.

\section{Resultados y discusión}

La activación directa de las vías de señalización a través de receptores de citocinas por las proteínas de la familia JAK, tiene un gran significado funcional ya que promueven la fosforilación del receptor y sirven de sitios de arribo para varias proteínas transductoras intracelulares $(10,11)$. La evidencia de la participación de JAK2 en la respuesta dada por varios miembros de la familia de proteínas HBP, le da una gran relevancia al estudio de los mecanismos en los que se ve involucrada esta cinasa. La baja producción endógena de JAK2 en células de mamíferos, característica de las proteínas transductoras, dificulta los ensayos in vitro de JAK2 con otras proteínas y, además, su aislamiento resulta difícil en la práctica. Por estas razones, se hace necesario utilizar un sistema en el que se exprese la proteína en mayor escala. Los vectores BEVS representan en la actualidad uno de los sistemas de expresión de proteínas eucarióticas más potentes y versátiles. Tienen la ventaja, entre otras, de que la proteina recombinante se obtiene, generalmente, en forma soluble y biológicamente activa $(12,13)$. Utilizando la construcción que contiene la secuencia codificante para la proteína JAK2 de ratón, iniciamos el estudio estableciendo las mejores condiciones para la infección, esto es: título del virus recombinante para infectar $1 \mathrm{x}$ $10^{6}$ células de insecto y tiempo óptimo de recolección de las células. 


\section{Evaluación del título de la solución viral}

El título de la solución viral se evaluó infectando 1 $\times 10^{6}$ células Sf9 con cantidades crecientes de la solución viral, analizando la proteína producida a las 72 horas postinfección y revelando con antiJAK2.

Como se observa en la figura 1, las células Sf9 infectadas con el baculovirus recombinante que contiene JAK2 de ratón, producen una proteína de $130 \mathrm{kDa}$ que es reconocida por el anticuerpo contra JAK2 y que corresponde a la masa molecular relativa estimada para JAK2 nativo (6), como también al peso estimado con base en la secuencia del CADN de JAK2 de ratón. Se obtuvo también una proteína de $97 \mathrm{kDa}$ reconocida por el anticuerpo contra JAK2 y que está presente tanto en las células infectadas como en las no infectadas, lo cual sugiere que se trata de una proteína constitutiva de las células Sf9.

Los resultados muestran que la producción de JAK2 aumenta en función de la concentración del virus y que tiende a estabilizarse, aunque, comparativamente, las diferencias en la cantidad de proteína sintetizada no son muy grandes dentro del rango de concentración de solución viral utilizada. La expresión de la proteína de $97 \mathrm{kDa}$ permanece semejante en todo el rango de concentración viral, lo cual confirma su origen constitutivo. A partir de bajas concentraciones de solución viral $(10 \mu \mathrm{l} / \mathrm{ml}$ de medio), es posible obtener una buena expresión de proteína recombinante. De esta manera, se decidió emplear en los ensayos posteriores la dilución que

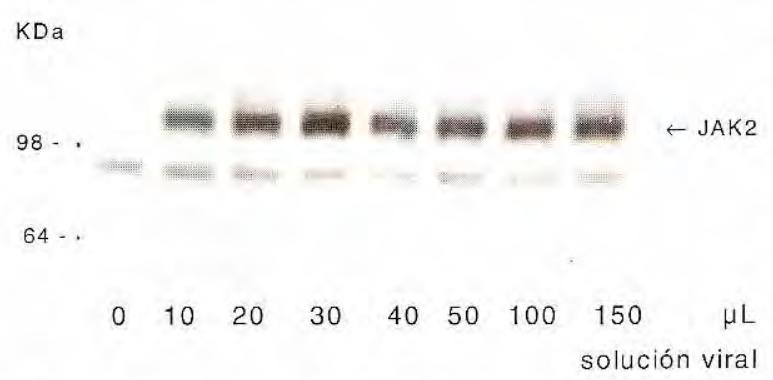

Figura 1. Evaluación del título de la solución viral al infectar células Sf9 y análisis por Western Blot de la proteína expresada, utilizando anticuerpo primarin anti-JAK2 (1:2.000) y secundario anti-conejo-lgG HRP (1:3.t.00). permitiera emplear el menor volumen de virus con un nivel adecuado de JAK2.

\section{Cinética de la infección viral}

La expresión de JAK2 al infectar $1 \times 10^{6}$ células Sf9 con una dilución de solución viral de $10 \mu \mathrm{l} / \mathrm{ml}$ de medio (figura 2), comienza a detectarse a las 24 horas después de la infección, encontrándose una meseta entre las 48 y las 72 horas postinfección. A partir de este tiempo, la expresión de JAK2 disminuye hasta que desaparece a las 144 horas.

En contraste, la proteína de $97 \mathrm{kDa}$ permanece relativamente constante hasta las 72 horas postinfección y empieza a disminuir a las 96 horas. Estos resultados confirman la naturaleza lítica del virus, la cual se manifiesta entre el cuarto y quinto día después de la infección (9). Los resultados de estos ensayos nos permitieron establecer las mejores condiciones de solución viral que se debe utilizar y de tiempo de recolección de las células postinfección en 72 horas, asegurando con ello una buena producción de JAK2 y, en lo posible, una menor expresión de la proteína de $97 \mathrm{kDa}$. Estos resultados son similares a los encontrados cuando se infectan células Sf 21 con un baculovirus recombinante que contiene JAK2 de rata (14), situación en la que la detección de JAK2 se da en bajos niveles a las 27 horas, aumentando y manteniéndose estable entre las 51 y las 123 horas postinfección. La producción de la proteína tiene, en este caso, un rango de tiempo mucho mayor comparado con nuestros resultados, lo que es inusual cuando se trabaja con este sistema.

A pesar de que el sistema utilizado permite contar con una buena producción de JAK2 recombinante, su expresión no es representativa con respecto a las demás proteínas contenidas en las células de insecto. Esto puede deberse a varios factores como la posible toxicidad de la misma proteína para las células, alguna falla en la construcción o la regulación del vector y, por último, a la ineficiencia de las vías secretoras existentes en las células de insecto infectadas con el baculovirus como se ha descrito para las proteínas CD4 e interleucina-4 murinas (15). En la mayoría de las construcciones de vectores informadas para varias proteínas, la producción de éstas es superior a 


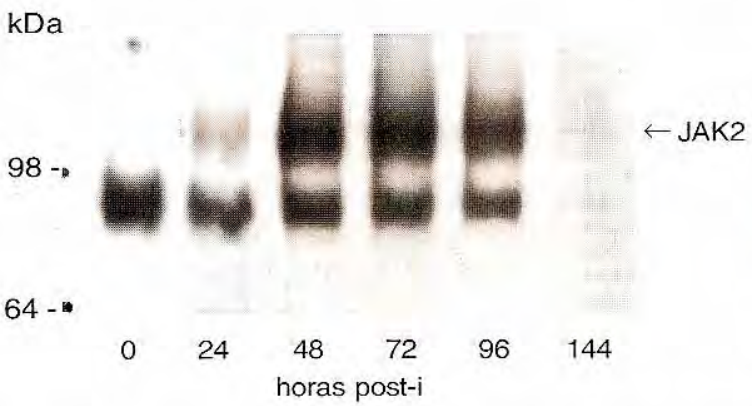

Figura 2. Cinética de la infección viral en células Sf9 y análisis por Western Blot de la proteina expresada.

$50 \%$. Este es el caso de la expresión de la proteína STAT5 de oveja, en la cual la tinción con azul de Coomassie evidencia que una gran proporción de las proteínas expresadas en las células infectadas corresponde a STAT5 (16). Al realizar la separación electroforética de las proteínas contenidas en las células de insecto (resultados no mostrados), no se alcanza a apreciar ninguna banda en $130 \mathrm{kDa}$. JAK2 puede visualizarse únicamente por Western blot. Lo anterior hace pensar que, probablemente, grandes cantidades de la proteína provocan la muerte de las otras células antes de que el virus logre infectarlas, impidiendo así su expresión en altos niveles.

\section{Actividad biológica de la proteína recombinante JAK2}

Al incubar extractos de células infectadas e inmunoprecipitados (IP) con anticuerpo contra fosfotirosina, puede observarse la presencia de una banda en $130 \mathrm{kDa}$ correspondiente a la proteína JAK2 (figura 3), la cual se intensifica con el tiempo, siendo de mayor intensidad a las 72 horas postinfección, cuando se encontró la mayor expresión de la proteína. Estos resultados nos están indicando que la JAK2 obtenida por baculovirus se encuentra fosforilada $y$, presumiblemente, catalíticamente activa.

Podría pensarse que, al igual que en los receptores con actividad tirosina-cinasa intrínseca, la oligomerización de los receptores de citocinas inducida por el ligando permite la aproximación de dos moléculas de JAK, promoviendo, así, la transfosforilación, situación que se simula al

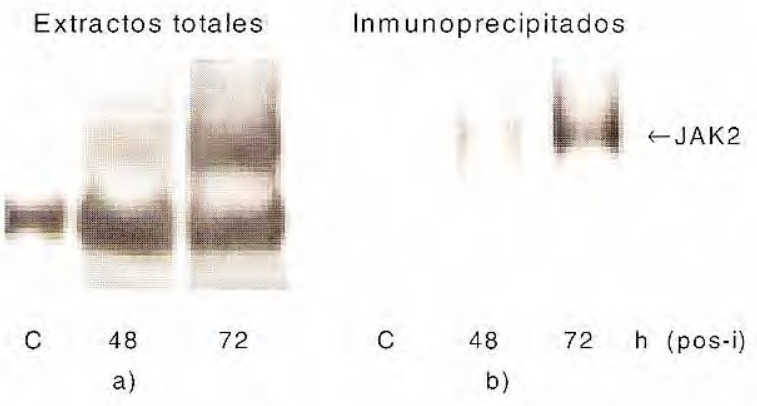

Figura 3. Western Blot de extractos celulares de células Sf9 e inmunoprecipitados, empleando anticuerpo primario anti-fosfotirosina PY20 (1:1.000) y secundario anti-ratón$\operatorname{lgG~HRP~(1:1.000).~}$

sobreexpresar JAK2 en baculovirus (16). Esto está de acuerdo con lo descrito por Quelle y colaboradores (17), quienes atribuyeron la fosforilación en tirosina de JAK2 a su 'sobreexpresión' en baculovirus, lo cual promueve de manera constitutiva su autofosforilación. La gran cantidad de moléculas de JAK2 permite que ocurra la transfosforilación, al igual que en presencia de receptores. No obstante, como lo afirma Duhé y colaboradores, la producción de JAK2 tiene que exceder un nivel crítico para que la transfosforilación ocurra espontáneamente (14). En nuestros resultados se puede observar que, necesariamente, el grado de fosforilación depende de la cantidad de moléculas de JAK2 presentes.

La autorradiografía correspondiente al ensayo cinasa (figura 4), muestra que en las células Sf9 infectadas con el baculovirus recombinante se está presentando fosforilación de una proteína en $130 \mathrm{kDa}$ correspondiente a JAK2. Estos resultados nos indican que la proteína JAK2 producida por baculovirus exhibe actividad de cinasa in vitro, presentándose posiblemente un intercambio en las tirosinas fosforiladas in vivo por ATP.

Por su parte, el control negativo (Sf9-control) presenta una banda de gran intensidad en $98 \mathrm{kDa}$, que puede atribuirse a la proteína endógena similar a JAK2 vista en la figura 1, lo que señala que esta proteína, además de ser reconocida por el anticuerpo, tiene también actividad cinasa, al tiempo que se está fosforilando en las células de insecto (figura 3a). Estos resultados son consistentes con la hipótesis de que las células Sf9 contienen una proteína cinasa endógena 


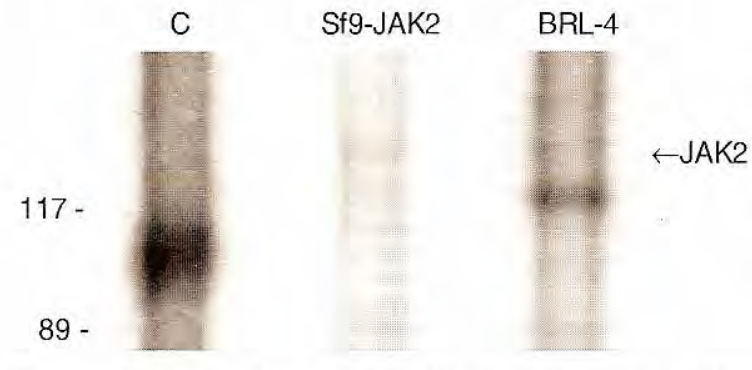

Figura 4. Autorradiografía de la electroforesis de los extractos celulares inmunoprecipitados con anti-JAK2 y proteína $A$-sepharosa $8 \mathrm{~B}$, fosforilados en presencia de $\left(\gamma^{32} \mathrm{P}\right)$-ATP.

semejante a las JAK cinasas, del mismo modo que en las células de Drosophila existe el producto del gen Hopscoth, identificado como una proteína cinasa de la familia JAK (18). Podría pensarse, entonces, que la regulación de la fosforilación de proteínas en este sistema está gobernada por mecanismos similares, incluso para la proteína recombinante. Esto implica que la purificación de la proteína recombinante sea un paso imprescindible.

En el control positivo (células BRL-4), se encuentra una banda muy tenue a la altura de $130 \mathrm{kDa}$ que corresponde a JAK2 expresada de forma endógena en estas células, lo que explica su menor actividad.

\section{Cromatografía de intercambio iónico}

La falta de un método de purificación para la proteína JAK2 nos llevó, por analogía con otras proteínas cinasas, a emplear la cromatografía de intercambio iónico como herramienta para este propósito $(17,19)$. Al someter el extracto total concentrado a una cromatografía de intercambio iónico en DEAE-Sephacel y eluir las proteínas retenidas con un gradiente de $\mathrm{NaCl} 10-500 \mathrm{mM}$, se obtuvo un primer pico entre las fracciones 3 y 23 (figura 5), correspondiente a las proteínas no retenidas en la columna; un segundo pico, entre las fracciones 91 y 111 y un tercer pico principal de mayor intensidad entre las fracciones 125 y 171.

El recuadro muestra la zona del tercer pico donde se detectó por inmunotransferencia la presencia de JAK2 en las fracciones 127 y 132 (figura 6). EI análisis para los picos 1 y 2 no arrojó respuesta positiva para JAK2.
Con el análisis por Western blot de fracciones del tercer pico, se logra observar que JAK2 queda retenida en la columna de DEAE y que es necesario aplicarle un gradiente de $\mathrm{NaCl}$ para que eluya. Aunque no se presenta una muy buena separación de las proteínas retenidas en la columna, se logró eliminar la proteína de $97 \mathrm{kDa}$ que es reconocida por el anticuerpo contra JAK2. A pesar de que este proceso de purificación concentra la proteína, aún no se logra su visualización por tinción con azul de Coomassie al concentrar las fracciones correspondientes al pico mayoritario (pico 3), así como sigue existiendo gran cantidad de proteínas en un amplio rango de pesos moleculares, sin que se aprecie la banda de $130 \mathrm{kDa}$ correspondiente a JAK2 (resultados no mostrados), lo que indica que la proteína continúa estando en muy bajos niveles con respecto a las otras proteínas celulares, sobre

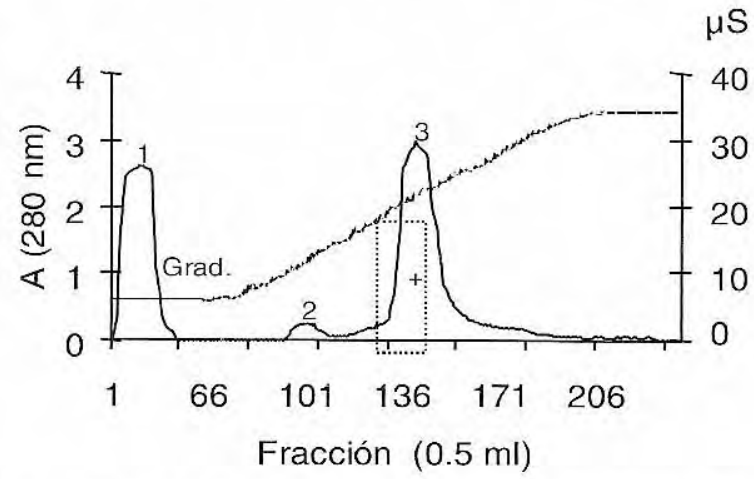

Figura 5. Perfil de elución en cromatografia de intercambio iónico (DEAE-sephacel) obtenido con los extractos celulares de Sf9 que contienen JAK2 recombinante.

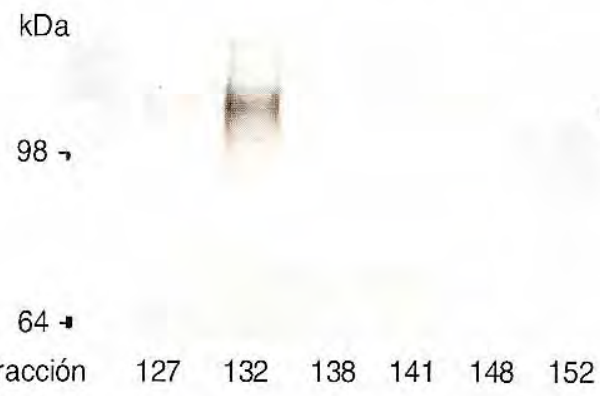

Figura 6. Análisis por Western Blot para JAK2 de las fracciones retenidas en DEAE-Sephacel. 
todo teniendo en cuenta que se partió de una buena cantidad de proteína proveniente de los extractos celulares.

De esta manera, sería necesaria una cromatografía de filtración en gel adicional para eliminar contaminantes de bajo peso y lograr una mejor purificación de la proteína. Otra forma de facilitar la purificación de JAK2 sería partiendo de una nueva construcción del plásmido bacteriano que contenga JAK2 y que, adicionalmente, cuente con un CADN que codifique para unos pocos residuos de histidina en un extremo de la proteína JAK2, lo que proporcionaría una buena alternativa para la purificación de JAK2 por cromatografía de afinidad utilizando resina Ni-NTA (20), de tal forma que sea posible su caracterización. Sin embargo, el método de purificación escogido en este trabajo es una buena alternativa inicial para la purificación parcial de la proteína JAK2 recombinante.

\section{Conclusiones}

La infección de células Sf9 con baculovirus recombinante conduce a la expresión de la proteina cinasa JAK2, aunque en una proporción menor que la encontrada para otras proteínas eucarióticas, expresadas por este mismo sistema.

La proteína recombinante obtenida en las células de insecto se expresa en un estado fosforilado y es capaz de fosforilarse in vitro, lo que indica que se encuentra catalíticamente activa.

La purificación parcial de JAK2 puede realizarse por medio de cromatografía de intercambio aniónico (DEAE-Sephacel). El peso molecular de la proteína recombinante estuvo en el rango de lo esperado (130 kDa).

\section{Agradecimientos}

Los autores agradecen al International Program in the Chemical Science (IPICS), Universidad de Uppsala, Suecia, por la financiación de este proyecto.

\section{Referencias}

1. Carter-Su C, Smit LS. Signaling via JAK tyrosine kinases: growth hormone receptor as a model system. Recent Prog Horm Res 1998;53:61-83.

2. Kishimoto T, Taga T, Akira S. Cytokine signal transduction. Cell 1994;76:253-62.
3. Skoda RC. Specificity of signaling by hematopoietic cytokine receptors: instructive versus permissive effects. J Recept Signal Transduct Res 1999;19:74172.

4. Ihle JN, Witthuhn B, Tang B, Yi T, Quelle FW. Cytokine receptors and signal transduction. Baillieres Clin Haematol 1994; 7:17-48.

5. Briscoe J, Guschin D, Rogers NC, Watling D, Muller $\mathbf{M}$, Hornet $\mathbf{F}$, et al. JAKs, STATs and signal transduction in response to the interferons and other cytokines. Philos Trans R Soc Lond B Biol Sci 1996;351:167-71.

6. Argetsinger LS, Campbell GS, Yang $X$, Witthuhn $B A$, Silvennoinen $\mathrm{O}$, Ihle $\mathrm{JN}$, et al. Identification of JAK2 as a growth hormone receptor-associated tyrosine kinase. Cell 1993;74:237-44.

7. Heim MH. The Jak-STAT pathway: cytokine signaling from the receptor to the nucleus. I Recept Signal Transduct Res 1999;19:75-120.

8. Hellgren G, Jansson JO, Carlsson LM, Carlsson B. The growth hormone receptor associates with jak1, jak2 and tyk2 in human liver. Growth Horm IGF Res 1999;9:212-8.

9. Ausubel FM, Brent R, Kingston RE, Moore DD, Seidman JG, Smith JA, et al. Expression of proteins in insect cells using baculoviral vectors. Current protocols in molecular biology. 2 zol. New York: Greene Publishing Associates and Wiley-Interscience; 1990

10. Ihle JN, Kerr IM. Jaks and Stats in signaling by the cytokine receptor superfamily. Trends Genet 1995; 11:69-74.

11. Carter Su C, Schwartz J, Smit LS, Smit LS, Meyer DJ, Billestrup N, et al. Molecular mechanism of growth hormone action. Annu Rev Physiol 1996;58:187-207.

12. Luckow VA, Summers MD. Trends in the development of baculovirus expression vectors. Biotechnology 1988;6:47-55.

13. Rohrmann GF. Nuclear polyhedrosis viruses. Enciclopedia of Virology. New York: Academic Press; 1994. p. $130-6$.

14. Duhe RJ, Farrar WL. Characterization of active and inactive forms of the JAK2 protein-tyrosine kinase produced via the baculovirus expression vector system. J Endocrinol 1995;147:11-23.

15. Kupsch J, Saizawa KM, Eichmann K. Expression of murine soluble CD4 protein in baculovirus infected insect cells. Immunobiology 1992;186:254-67.

16. Flores A. Estudio de los mecanismos de acción celular en la familia de la hormona de crecimiento y la prolactina (tesis). Santa Fe de Bogotá: Universidad Nacional de Colombia; 1997. 
17. Quelle FW, Thierfelder W, Witthuhn BA, Tang B, Cohen S, Ihle JN. Phosphorylation and activation of the DNA binding activity of purified Stat 1 by the Janus protein-tyrosine kinases and the epidermal growth factor receptor. J Biol Chem 1995;270:20775-80.

18. Binari R, Perrimon N. Stripe-specific regulation of pairrule gene by hopscotch, a putative Jak family tyrosine kinase in Drosophila. Genes Dev 1994;8:300-12.
19. Kitagawa M, Mukai H, Shibata H, Ono Y. Purification and characterization of a fatty acid-activated protein kinase (PKN) from rat testis. Biochem J 1995;310:65764.

20. Polayes D, Harris R, Anderson D, Ciccarone V. New baculovirus expression vectors for the purification of recombinant protein from insect cells. Focus 1996;18:10-3. 